\title{
Introducing Innovative Technologies in Higher Education: an experience in using Geographic Information Systems for teaching-learning process
}

\author{
Raquel Pérez-delHoyo, Higinio Mora, Pablo Martí-Ciriquián , María L. Pertegal-Felices, Rafael \\ Mollá-Sirvent
}

\begin{abstract}
In today's world, new technologies are coming into the classroom. The use of them to support learning can provide significant advantages for teaching-learning process and have potential benefits for students since many of these technologies are part of the work life of many current professions. The aim of this work is the analysis of using innovative technologies for engineering and science education after analyzing the data obtained from students in their learning process and experiences. The study has been focused on computational Geographic Information Systems, which allow access to and management of large volumes of information and data, and on the assessment of this tool as a basis for a suitable methodology to enhance the teaching-learning process, taking into account the great social impact that big data is generating. The results allow identifying the main advantages, opportunities and drawbacks of using these technological tools for educational purposes. Finally, a set of initiatives have been proposed to complement the teaching activity and to improve user experience in the educational field.
\end{abstract}

Keywords.- Learning analytics; experiential learning; innovative technologies; enhanced science $\&$ engineering education; geographic information systems

\section{INTRODUCTION}

The development of education-oriented technology, virtual training and Internet as a vehicle for learning has generated a large volume of data that offers academic researchers valuable information about how these technologies are being used and how can be improved to enhance their objectives for learning-teaching process (Mora et al., 2020).

Geographic Information Systems (GIS) can be described as a digital system for the acquisition, management, analysis and visualization of spatial data for the purposes of planning, administration and monitoring the natural and socio-economic environment. In a widest sense, a GIS can represent a complete digital model of the geography (Longley et al, 2015). The field of GIS is concerned with the description, explanation and prediction of patterns and processes in geographic scales. Therefore, GIS are not just a technology but a science and a problem-solving methodology, using knowledge of the geoscientific reality (Bitting et al., 2018). 
In many areas, GIS are formidable tools to develop professional activities. For example, the management of resources, urban planning and identification of the territory's potential, optimization of transport routes and logistics activities require a practical application of spatial analysis. Moreover, in the scientific field, GIS technology can provide a uniform platform and data structure for spatial computing problems (Yu et al., 2020), and has the potential to reveal a priori unseen knowledge in geographic information such as patterns, relationships or nonobvious anomalies to the simple observation (Chen and Zhuang, 2020). This definition introduces the ability of GIS as a tool of analysis and generates new perspectives.

GIS are one of these key technologies for the development of Science, Technology, Engineering and Mathematics (STEM) curriculum and it a protagonist tool for the digital transformation in higher education (Abad-Segura et al., 2020; Jant et al., 2020).

This innovative technology enables learning through experiences based on spatial visualization and analytical functionality (Baker, 2015), and allows developing the key components of spatial thinking, geographical knowledge and, spatial citizenship (DeMiguelGonzález and DeLázaro-Torres, 2020).

Due to these significant implications for the professional world, the study of GIS has been included as part of the curriculum of many STEM degrees. It is an innovative technology that students must know as part of the computer skills to guarantee their professional performance (Powell, 2020). But the use of GIS in education is not just limited to learning the tool, it also provides new opportunities to understand and make sense of the modern world as stated by "International Geographical Union" (Stoltman et al., 2017). For example, making the most of its technological features such as dynamic nature of the data for visualizing the evolution of land use over the time (Xie et al., 2020), performing further spatial analysis of the data derived 
from remotely sensed images (Wang et al., 2020) and making more accurate and precise surface analysis with 3D GIS (Moore et al., 2020), among others.

GIS technology is potentially the basis of applying an active learning methodology because it increases motivation, interest in classes and stimulates students' curiosity in discover de world around them (Jo et al., 2016; DeMiguel-González and DeLázaro-Torres, 2020). To this end, GIS tools shows how acquired knowledge can be applied in practice and establishes connections with everyday applications and professions (Healy and Walshe, 2020).

However, the use of GIS in education finds challenges that must be addressed, mainly due to the heterogeneity of platforms, the different professional profiles involved, and the variety of information available for analysis. There is not a clear body of knowledge to unify criteria and results. This situation opens new opportunities for innovation in the design and development of innovative technologies for education (Baker, 2015; Bearman et al., 2016). This paper takes a step forward in that direction. The aims of the research are to study the potential of GIS as a basis for learning methodology and to identify the main problems and challenges of designing an academic-oriented GIS. For these purposes, the research method used has been based on the analysis of the learning experiences obtained from students and teachers. Finally, for each of the challenges identified, some ideas and initiatives have been proposed to solve the problems detected, taking advantage of the opportunities offered by the new proposals for the development of advanced web-based systems.

The research group of this work consists of two computer engineers, two specialists in urban planning and an educational psychology specialist. It is this multidisciplinary nature of the research group that has allowed a sufficiently broad vision of the opportunities of GIS as a learning methodology to be constructed, as well as the main problems and challenges of 
designing an academic-oriented GIS to be identified, with a multifaceted approach that takes into account various points of view.

The rest of the paper is organized as follows: Section 2 describes a related work that includes an introduction to GIS in Higher Education and a compilation of the main issues and works in this area. From this point, Section 3 then focuses on the study of the potential of GIS as a basis for learning methodology through the analysis of the learning experiences obtained from students. This experience allows the advantages, opportunities and main drawbacks of GIS tools for educational purposes to be identified. Finally, Section 4 concludes with a discussion of the contributions and future work.

\section{RELATED WORK}

The following subsections discuss the relevant studies related to this research. A final subsection is added which outlines the main findings and issues raised in the previous work.

\subsection{Introduction to GIS in Higher Education}

This subsection deals with the introduction of this tool in the university curricula and student engagement with GIS.

GIS have been initially linked to those studies related to Geography; however, the diversity of uses of the georeferencing has allowed GIS to be considered as useful tools in a wide variety of educational areas. Thus, the incorporation of georeferencing in several important areas can be identified: Geography and the Earth Sciences-Geology, Environment, and other related disciplines (Norton et al., 2019), which have based the use of GIS in the analysis and planning of territorial spaces; Urban and Regional Planning (Afrooz et al., 2019), linked to the territorial intervention as Engineering and Architecture that have been found in these systems a few new tools for the project; Computer Science related to Robotics and Georeferenced Applications 
oriented to the production of applications and robots which based its activity on geolocation (Dardas, 2018); Geomatic Engineering for which the georeferencing is indispensable to its functioning (Basaraner et al., 2014); and, finally, the Cartographic Engineering, converted into an independent discipline, that in addition to developing an environment autonomous discipline provides tools for application to other fields of knowledge (Ooms et al., 2015).

In the university teaching level, the importance of GIS technology begins to be reflected with greater intensity at the end of the 1990s. The first specific University Master Studies focused on geographic information technologies were develop at the beginning of the 21st century (Korucu, 2012). Since then, the use of GIS in teaching has evolved from a basically theoretical orientation to a practical and applied design mainly thanks to the implementation of Spatial Data Infrastructures (SDIs) and free and open source software for GIS.

This evolution reflects in itself the progress and discovery of the potentialities of GIS in higher education, capabilities that go beyond the mere teaching of GIS software. It is the mode in which these systems have opened up new possibilities in the way of approaching teaching and being really very relevant to "learn by doing", also coinciding with the challenges posed by the harmonization of the European Higher Education Area (EHEA). GIS provide teaching models oriented to the student to develop and lead their learning independently. In addition, they bring us new active educational practices and, above all, to the creation of a new more sensitive social conscience in line with the world we inhabit.

In general terms, the learning outcomes that can be developed by applying GIS tools are transversal to many areas: GIS tools provide students closer and new dynamic forms of relationship with knowledge (both to acquire and represent it) and they are of great help to know and understand theoretical concepts. For example, students of Earth Sciences in Geology should 
be interested in using GIS to better know the geographic features of the earth form a further level of detail and with from another perspective (aerial views, 3D mapping, etc.); students of Urban planning in Architecture should be interested in using GIS to understand how the city works, how cities have evolved over the years, and to represent new urban designs of the city. In this way, as future professionals, students of many disciplines must acquire skills and knowledge related to the opportunities offered by GIS. Thus, many of the capabilities of the GIS tools come to discover the educational objectives (Jant et al., 2020) and construct new knowledge from land data (Rickles and Ellul, 2015).

Some objectives aim to achieve specific skills. In this regard, the services offered by GIS to society include the following (Ricker and Thatcher, 2017): providing effective means for the management and distribution of spatial data, facilitating the collection, organization and storage, minimizing the duplication of data, integrating information from many sources; providing analysis or complex queries relating georeferenced data to generate new knowledge; optimizing the efficiency of planning and decision making, simulating the consequences of applying different assumptions or models. The general skills of research, representation, and interpretation are also enhanced by GIS. With its application arise opportunities for integrating experience, critical reflection, and virtual applications. Accordingly, there are five generic questions that GIS can answer as a support to the learning process: What can be found in a particular place?, In which places can be identified common characteristics?, What has changed in a place during a particular time?, What spatial patterns are checked or what trends of change can be recognised?, What would happen if this or any other specific model would be adapted?

Other educational objectives have to do with the acquisition of skills of basic and transversal nature. GIS contributes to improve spatial ability of students with other academic 
disciplines and technological tools such as Virtual Reality (Molina-Carmona et al., 2018.). It is important that students understand the role these technological tools in the current information society, its presence and influence, understanding that the knowledge of the world requires the integration of knowledge from various disciplines. Understanding this reality and the potential of GIS will guide the education to train engaged and informed citizens, increasing both their comprehensive capabilities- to use, manage and relate large amount of geographic information - and analytical capabilities - to anticipate and respond to future conflicts or complex situations, quickly, efficiently and safely.

\subsection{Application of GIS in the teaching-learning process}

This subsection compiles de main works which apply GIS tool as part of the teachinglearning process. As the importance of using GIS in teaching-learning process increases, there are more research works studying their effects and potential of this tool in education. This theme is both extensive and well debated, which is focusing on several fields such as knowledge acquisition, frameworks, development of skills, challenges, student engagement, etc. Therefore, in this work only the more relevant topics and works have been cited as representative of the intensive research that is taking place. Table 1 summarizes the main topics and contributions of each of them.

TABLE 1: Main topics and contributions of GIS in education

\begin{tabular}{ll}
\hline Topic/work & Contribution \\
\hline Acquisition of geographical knowledge \\
\hline (Healy and Walshe, 2020) & GIS training develops students' perceptions of the value and nature of GIS \\
& and its impact on their geographical knowledge. \\
(DeMiguel-González and & Discusses the implications of implementing geospatial technologies to \\
DeLázaro-Torres, 2020) & acquire spatial thinking and geographical knowledge. \\
(Powell, 2020) & Using Geospatial Technology to Promote Middle School Students' Critical \\
& Thinking on Socioscientific Issues.
\end{tabular}

Framework for teaching GIS and improving learning experience 
(Ricker and Thatcher, 2017)

(Bitting et al., 2018)

(Baker, 2015)

(Wang et al., 2020)
Propose an applied pedagogical framework for teaching cutting-edge GIS material.

Examines the impact of a Google Earth-based exploration assignment on conceptual understanding in introductory geoscience courses

the growing educative role for webGIS is explored. Pedagogical and technical considerations are discussed.

Gives an overview of current teaching and learning structures with Digital Earth technologies.

GIS develops students' critical thinking, spatial reasoning and problem solving

(Kim and Bednarz, 2013) This work investigates the effects of GIS learning on three components of critical spatial thinking.

(Jant et al., 2020)

GIS-based instruction can be used to enhance students' use of spatial reasoning when solving STEM-relevant problems.

(Jo et al., 2016)

The findings indicate that Web-based GIS activities significantly enhanced students' spatial thinking skills.

(Bearman et al., 2016)

This work evaluates how this contributes to critical spatial thinking.

(Xiang and Liu, 2019)

This study investigates the extent that different learning styles exert an influence on spatial thinking of students.

Challenges of Learning GIS

(Rickles and Ellul, 2015)

This paper examines some of the challenges facing learners of GIS in interdisciplinary research projects.

(Mathews and Wikle, 2019)

This study assesses the pedagogical approaches used to teach GIS\&T courses and identifies the challenges associated with teaching GIS\&T.

(Han, 2019) The transmission of capabilities, opportunities and challenges for educators and students is discussed.

Engagement of Students

(Norton et al., 2019);

This work Investigates the impacts on student engagement and perception of the incorporation of GIS technology.

(Egiebor and Foster, 2019)

This study analyses the students' perceptions of their engagement using GIS-Story maps.

(Corrales-Serrano et al., 2019)

This work study the usefulness of GIS as educational tools as well as a motivational factor in the study of historical heritage.

(Goldsmith, 2016)

This case study investigates the potential use of GIS as a means to increase students' engagement.

\section{Support Collaborative Learning and Teaching}

(Afrooz et al., 2019) GIS provides opportunities to facilitate team communication and a route to more collaborative leaning.

(Spielman, 2014) This work analyses the spatial collective intelligence.

Active learning strategies

(Livingstone and Lynch, 2010) This article compares two experiences of Active Learning group-based student projects in GIS and Geography degree modules.

(Peirce, 2016)

This work introduces to using simple mobile GIS technologies as an active learning tool for teaching undergraduate Geography students.

(Carlson, 2007)

This article describes a pedagogic foundation for introducing a field-based GIS experience and uses a dual evaluation methodology to monitor student learning and satisfaction.

(Elwood, 2009)

This paper explores some of the unique opportunities and challenges of integrating participatory action research into undergraduate GIS courses. 


\section{LEARNING METHODOLOGY BASED ON USING GIS}

\subsection{Research process: Methodological considerations}

As mentioned previously, GIS technology presents significant challenges and opportunities for higher education. Technological advances have made GIS easily accessible from a variety of platforms and this has already affected the way issues can be addressed, including in higher education. Continued adaptation to rapid technological advances is not easy and is a major challenge. However, the possibility of incorporating a new innovative perspective in STEM education based on intelligent consumption of information and spatial analysis is an opportunity that, in today's knowledge society, cannot be ignored by teachers. In this sense, to reflect on the potential of GIS as a learning methodology, the research process is based on the formulation of two research questions:

(A) Why should efforts be focused on GIS education and what is the impact of applying GIS in teaching-learning processes?

(B) Is GIS as a methodology more effective than other methods for education?

To answer these research questions, an analysis of the learning experiences obtained from the students of a group of urban planning subjects of the Degree in Fundamentals of ArchitectureUniversity of Alicante (UA), Spain-has been developed. The study includes the compulsory subjects Urban Planning 1 of second year (https://cvnet.cpd.ua.es/GuiaDocente $/$ ?lengua $=$ en\&wcodasi $=35514 \&$ scaca $=2019-20)$ and Urban Planning 6 of fifth year (https://cvnet.cpd.ua.es/Guia-

Docente/GuiaDocente/Index?wlengua=en\&wcodasi=35544\&scaca=2019-20). These are not specific subjects on spatial analysis of data or methods of urban research, but basic subjects of the discipline of Urbanism that have traditionally been taught through theoretical sessions and 
with the support of some practical exercises, which students usually perform with the use of Computer Aided Design (CAD) programs. Therefore, the integration of GIS as the basis for methodology in the teaching-learning processes of these subjects should be considered an important teaching innovation.

Table 2 below describes the sample of students involved in the teaching-learning experience that has served to carry out the study, with additional information on gender and number of students taking the subject for the first time. Almost all students whose learning experience has been analysed were taking the subjects for the first time, with a few exceptions. However, to properly assess the impact of applying GIS in teaching-learning processes it is necessary to take into account that, in the case of Urban Planning 1, being a second year subject, the degree of uncertainty of students is higher, compared to the case of Urban Planning 6 in which, being a fifth year subject, students already have some previous knowledge of GIS.

TABLE 2: Students involved in the teaching-learning experience

\begin{tabular}{|c|c|c|c|c|c|c|c|c|c|c|c|c|}
\hline $\begin{array}{l}\text { Academic } \\
\text { year }\end{array}$ & \multicolumn{3}{|c|}{$2015 / 16$} & \multicolumn{3}{|c|}{ 2016/17 } & \multicolumn{3}{|c|}{$2017 / 18$} & \multicolumn{3}{|c|}{ 2018/19 } \\
\hline Subject & $\mathrm{F}$ & $\mathrm{M}$ & $1^{\mathrm{st}}$ & $F$ & $M$ & $1^{\mathrm{st}}$ & $\mathrm{F}$ & $\mathrm{M}$ & $1^{\mathrm{st}}$ & $\mathrm{F}$ & $\mathrm{M}$ & $1^{\mathrm{st}}$ \\
\hline \multirow{2}{*}{$\begin{array}{l}\text { Urban } \\
\text { Planning } 1\end{array}$} & 26 & 39 & 62 & 36 & 26 & 60 & 15 & 15 & 30 & 14 & 21 & 35 \\
\hline & \multicolumn{3}{|c|}{65} & \multicolumn{3}{|c|}{62} & \multicolumn{3}{|c|}{30} & \multicolumn{3}{|c|}{35} \\
\hline \multirow{2}{*}{$\begin{array}{l}\text { Urban } \\
\text { Planning } 6\end{array}$} & & & & & & & 6 & 13 & 19 & 13 & 17 & 29 \\
\hline & & & & & & & & 19 & & & 30 & \\
\hline
\end{tabular}

F: Female; M: Male; 1st: First enrolment

The methodology that has been used to develop the research has focused on the analysis and assessment of two fundamental aspects, firstly, the attitude of the students towards the learning experience, the degree of motivation, confidence and autonomy; and secondly, the learning outcomes, in each case in accordance with the achievement of the teaching objectives. It 
has been assumed that there is a close direct relationship between these two factors, so that no separate study can be carried out, but rather a set of both indicators.

The assessment of both fundamental aspects, students' attitudes and learning outcomes, has been carried out at three different moments throughout the research, first, at the beginning of the experience to assess the degree and speed with which it is possible to capture the students' attention and obtain the first results; second, throughout the development of the experience to assess the learning curve with greater or lesser ups and downs and the evolution of the degree of motivation; and third, at the end of the experience to have an overall assessment of all the learning outcomes obtained as well as the students' maintained attitude and their degree of autonomy. The final objective is to be able to compare these assessments with previous experiences developed using other more traditional methodologies.

As mentioned above, for these subjects, the use of GIS as the basis for teaching methodology implies a radical change in students' experience and learning results. In this paper, we aim to describe the benefits and problems we have found as well as to propose some solutions to address these problems.

In terms of resources, the use of GIS applications offered by public administrations is encouraged as technological tools, mainly due to the great variety and exhaustiveness of the information they offer. Through these applications provided mostly through Internet web platforms, students can easily access the information and analyse the large amount of georeferenced data that is necessary to develop the proposed activities in the course. With regard to materials, the volume of information from these GIS systems reaches up to $80 \%$ of the total information that students manage to achieve the learning objectives. 


\subsection{Teaching experience: Activities and tools}

There are several teaching-learning methodologies based on GIS tools. For example, how knowledge is constructed in active land data research from GIS. This outcome allows them to design their own data analysis to find out the required knowledge in each case.

This subsection describes briefly a series of practical activities on the use of GIS applications in teaching of urban planning, in order to discuss the potential of GIS in designing learning methodologies and introduce the main challenges involved in their use. The learning activities described are focused on the educational objective of studying the territory and the current urban planning of cities:

a) Study of dynamic geographic information to know the evolution of the geographical area of a city. In this activity, students must analyse several aspects of the selected areas: how they are formed, how they have grown and how the territory has been occupied to nowadays. In this activity, the knowledge is constructed from queries to a GIS platform.

b) Analysis of static geographic information to identify and explain the parts that shape the city: the historical centres, the first extensions, the subsequent land-use plans, the last recent growth plans, the new developments planned and tourist areas. In this activity, students become familiar with some theoretical concepts.

c) Study of the territory to determine potential land uses. In this activity, students identify the existing areas in the territory: residential, industrial and tertiary urbanized lands, protected and common rural lands according to their capacities of use. It is shown how remote sensing data are useful to build this land information.

With these activities, the students are expected to learn urban planning matters (city area evolution, city shape and study of the territory). Before addressing the proposed activities, 
students face the challenge of navigating the SDI platforms, which constitute a great potential for the development of the knowledge society. A brief tour is enough for students to become aware of the wide range of spatial information available and the importance of using it wisely. Understanding the complex process of working with large-scale geographic data encourages them to begin exploring the potential of GIS. In this way, the predisposition of students is very positive and it is in line with the educational objectives (Argles, 2017).

In the case of the activity (a), the following figure (Fig. 1) shows the maps produced by the students to analyse the occupation of the territory in the geographical area of Valencia in Spain (Lat.: 39.4077013; Long.:-0.5015955). To get these results, with the guidance of teachers, they have to choose between different categories of spatial software such as web map servers, spatial database management systems or web map development toolkits. On the other hand, during the learning process, it is the students themselves who have to select and design, within the wide range of possibilities offered by the GIS applications, the series of exercises-queries and analysis - which must be done to achieve the goals. In this way, GIS enables students to learn actively and responsibly.

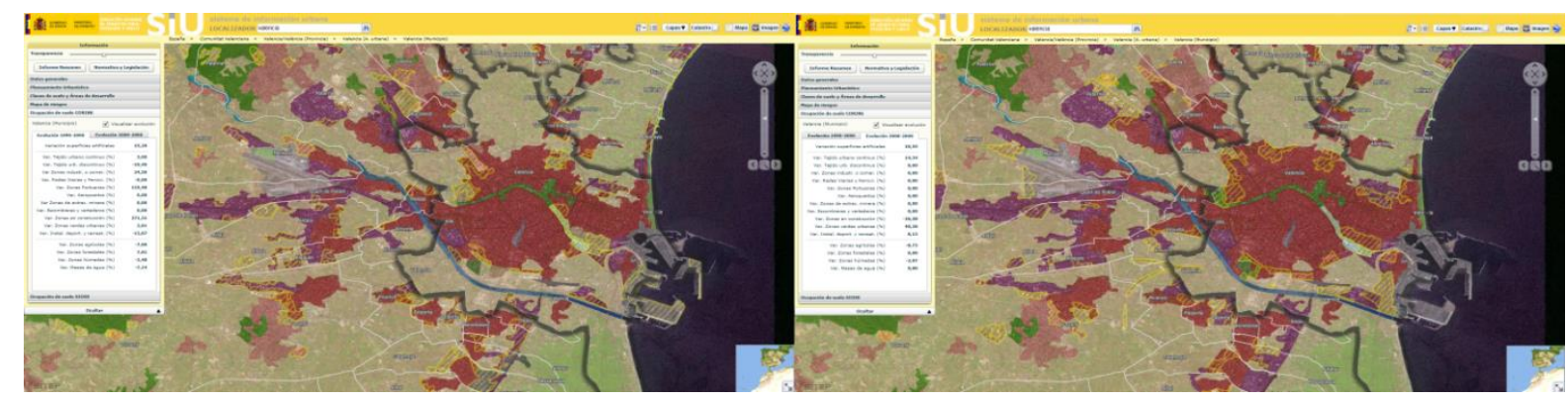

Fig 1. Example of dynamic geographic information study. GIS Application used: Urban Information System (http://visorsiu.fomento.es/siu/PortalSiu.html\#).

Fortunately, the Internet and new technologies have a transversal use in many subjects and the college students have good technological skills. The use of GIS applications, with 
increasingly more intuitive interfaces that do not require complex user-skills, therefore, it is not a problem for students. They quickly become familiar with the use of these applications and they do not require previous training requirements. This fact favourably influences their learning perception and allows them to focus on specific concepts of the subject. For this reason, the use of GIS facilitates the self-regulated learning as they introduce an extra motivational aspect that is fundamental to awaken students' interest and to enrich the learning environment (Argles, 2017; Ricker and Thatcher, 2017). For example, the following figure (Fig. 2) shows the result of the analysis carried out on the students' own initiative to determine, after knowing the growth of the geographical area of Valencia - activity (a) - , which are the new areas of development planned by the municipality—activity (b)—.

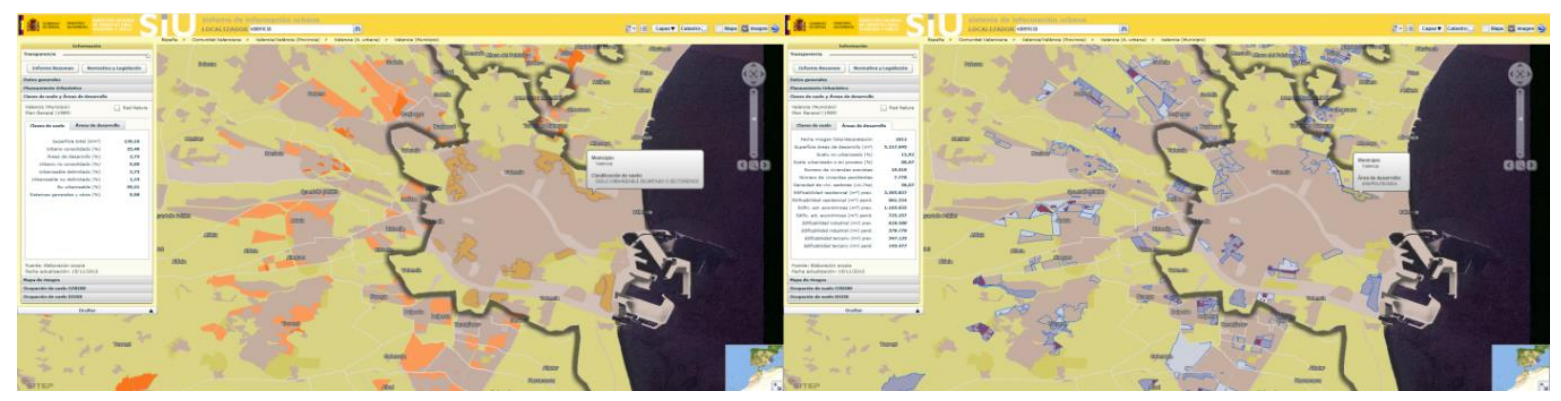

Fig 2. Example of static geographic information study. GIS Application used: Urban Information System (http://visorsiu.fomento.es/siu/PortalSiu.html\#).

In the classroom, the teacher can show a pair of examples of each concept. Moreover, GIS tool allows to look for unlimited examples of these concepts along all the world. Students can see cases from the cities where they live, and to ask questions about it to the teacher.

In addition, students also have the possibility to add cadastral information to the results and combine them with other information such as population data. For this purpose, it is an opportunity in the teaching of urban planning subjects the use of free GIS software and mapping. For example, the following figure (Fig. 3) shows the result of the analysis carried out by the 
students to study the distribution of the population - inhabitants per hectare - in the administrative sections of the municipality of Móstoles in Madrid, Spain (Lat.: 40.3231193; Long.:-3.9026507). Both the cartographic database and the population data have been provided for teaching purposes by the public administrations.

As the course progresses, students are able to perform more elaborate analyses. For example, the following figure (Fig. 3) shows the result of identifying the areas in the city of Valencia that meet the necessary conditions to develop a certain activity. In this case, the following conditions were chosen: more than $65 \%$ of the resident population is between 16 and 64 years old, more than $45 \%$ of the population has university studies and, in addition, the area has more than $35 \%$ of homes owned.

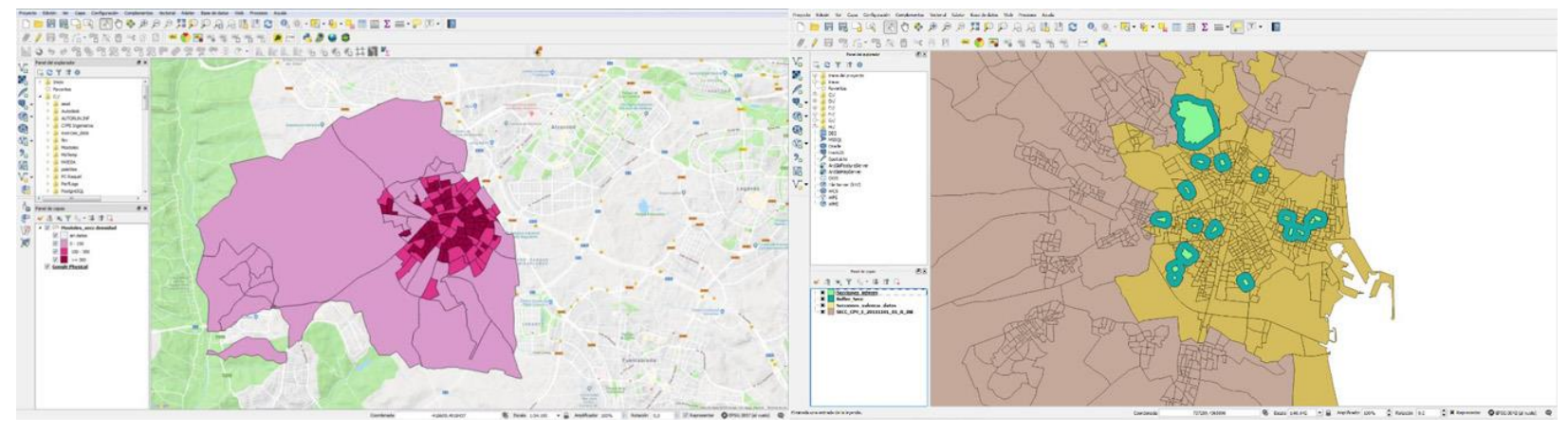

Fig 3. Example of GIS analysis using free and open source software. GIS Application used: QGIS 2.18.16. (https://www.qgis.org/en/site/)

More examples are shown in the following figure (Fig.5). On the left is a study of the structure of the urban economy in the historical centre of the city of Pamplona in Spain (Lat.: 42.8168700; Long.:-1.6432300), mapping the different activities to draw conclusions from their location. On the right is a study of the height of buildings in the historical centre of the city of Salamanca in Spain (Lat.: 40.9559681; Long.:- 5.6802244).

Another important issue refers the personal involvement that the use of GIS requires from students. A priori, a requirement that is positive, because if the education should be for life, 
personal experience persists longer. Using GIS technology, students should ask questions about topics such as scale, precision, the influence and the scope of analysis that lead to results, even on the ways in which humans interact with computers. Answering these questions requires systematic research, as well as dealing with different disciplines, leaving understand these separated from the knowledge of the world (Longley et al, 2015). GIS provide challenges to students, avoiding the monotonous work and stimulating education (Argles, 2017). The motivation of the student minimizes the problems (Goldsmith, 2016; Egiebor and Foster, 2019; Norton et al., 2019).
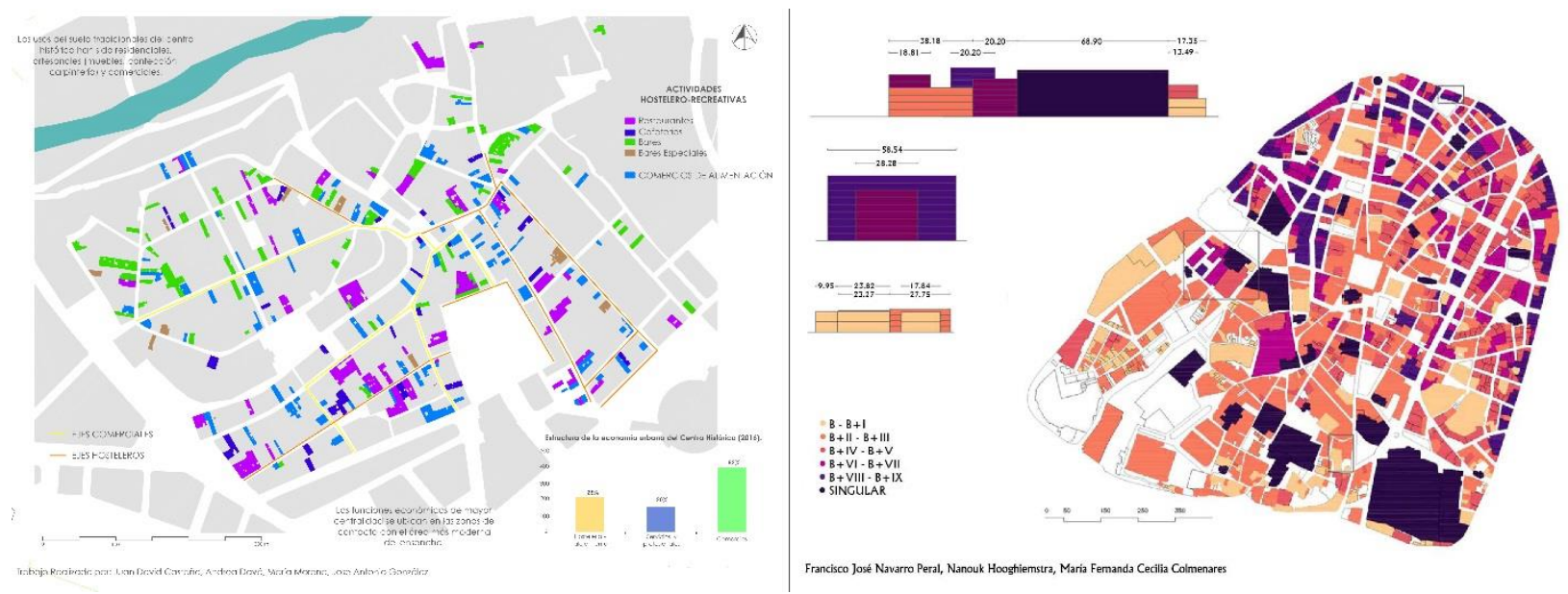

Fig 5. Examples of work carried out from GIS analysis. GIS Application used: QGIS 2.18.16 (https://www.qgis.org/en/site/).

In addition, it is the responsibility of higher education engaging students in the sustainability debate. It is a chance to enhance the quality of the learning process. In this respect, the following figure (Fig. 6) shows the maps made by the students to analyse the potential of the territory in the municipality of Elche in Alicante, Spain (Lat.: 38.2730442; Long.: -0.7265599) —activity (c) - . To obtain these results, they must identify protected natural lands and areas of environmental interest, becoming aware of the value of the territory and the need to move towards a sustainable development model. 


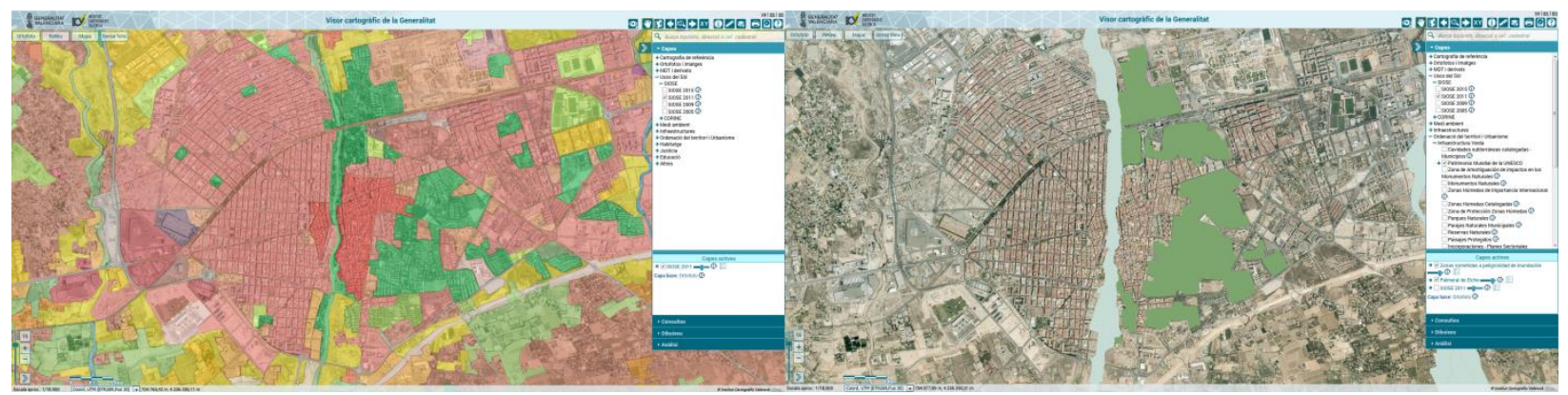

Fig 6. Example of land uses study.

GIS Application used: Cartoweb (https://visor.gva.es/visor/).

The following figure (Fig. 7) shows an example of the final result achieved by the students, once they have completed the GIS analysis and exported the corresponding thematic map with the conclusions of the study carried out. In this case, the potential of the territory in the municipality of Novelda in Alicante, Spain (Lat.: 38.3775747; Long.: -0.7844233) has been studied. The data have been downloaded from the Cartoweb application and the analysis has been carried out in QGIS.

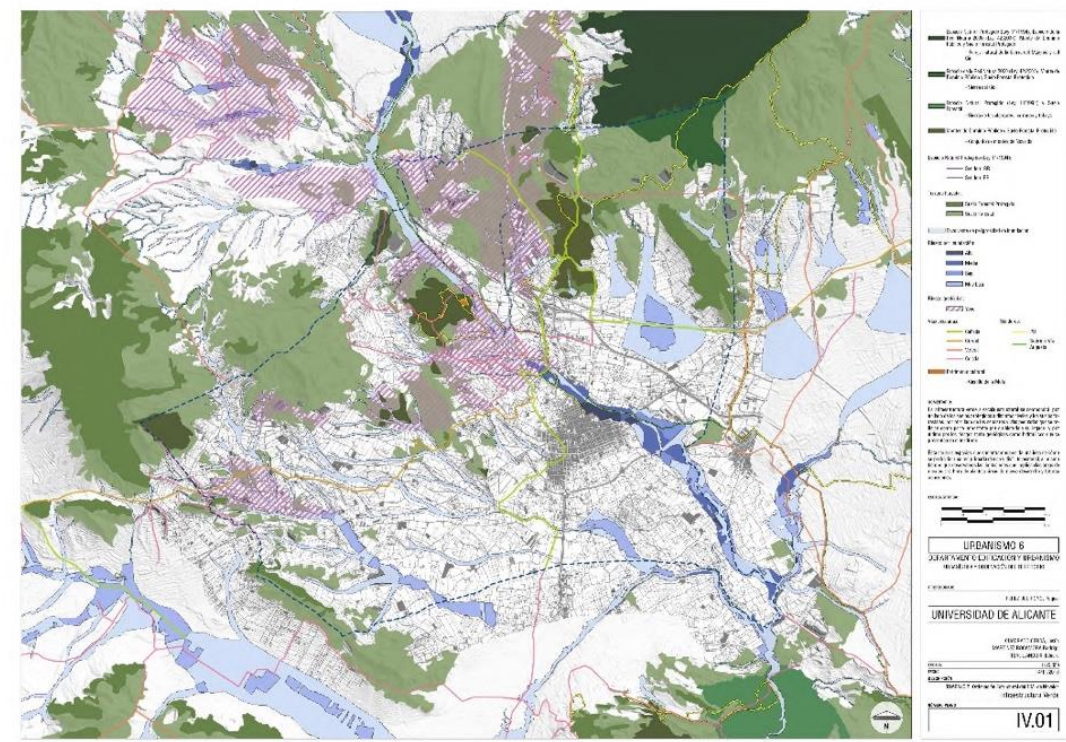

Fig 7. Example of land uses study. GIS Applications used: Cartoweb and QGIS. In addition, other post-production programs have been used.

Learning methodology based on using GIS is sensitive to the natural and cultural environment. It offers students an effective new way of relating to knowledge that allows them to 
become aware of the real needs of the world and find possible solutions to complex problems. Every problem has a particular place in the world. As can be seen, there is now a wide range of GIS software options that allows students to work with flow of spatial information from different sources. It is therefore very important to make recommendations to students on the good use of the resources during the learning process. The applications most commonly selected and used by students in the activities described are presented in Table 3.

TABLE 3: Main GIS tools used by students.

\begin{tabular}{|c|c|c|}
\hline GIS description & URL & Description \\
\hline \multicolumn{3}{|l|}{ Spanish Scope } \\
\hline $\begin{array}{l}\text { Urban Information } \\
\text { System }\end{array}$ & http://visorsiu.fomento.es/siu/PortalSiu.html & $\begin{array}{l}\text { Urban planning } \\
\text { Land use }\end{array}$ \\
\hline $\begin{array}{l}\text { Digital Atlas of Urban } \\
\text { Areas }\end{array}$ & http://atlas.vivienda.es & $\begin{array}{l}\text { Statistical data } \\
\text { Thematic maps }\end{array}$ \\
\hline Iberpix & $\begin{array}{l}\text { http://www2.ign.es/iberpix/visoriberpix/visorign } \\
\text { html }\end{array}$ & $\begin{array}{l}\text { Cartography } \\
\text { Land use }\end{array}$ \\
\hline $\begin{array}{l}\text { National Plan for Aerial } \\
\text { Orthophotography }\end{array}$ & http://pnoa.ign.es/vuelo-fotogrametrico & Aerial photographs \\
\hline Digital Photo Library & $\underline{\text { http://fototeca.cnig.es }}$ & Aerial photographs \\
\hline CARTOCIUDAD & http://www.cartociudad.es/portal & Cartography \\
\hline $\begin{array}{l}\text { SIOSE } \\
\text { (Land Use Information } \\
\text { System) }\end{array}$ & http://www.siose.es/ & Land use \\
\hline $\begin{array}{l}\text { Cadastral Electronic } \\
\text { Office }\end{array}$ & https://www.sedecatastro.gob.es/ & $\begin{array}{l}\text { Cadastral information } \\
\text { Cartography }\end{array}$ \\
\hline $\begin{array}{l}\text { Spanish Statistical } \\
\text { Office }\end{array}$ & http://www.ine.es/ & Statistical data \\
\hline $\begin{array}{l}\text { CARTOWEB } \\
\text { (Only for the Community } \\
\text { of Valencia Region) }\end{array}$ & http://visor.gva.es/visor/ & $\begin{array}{l}\text { Urban planning } \\
\text { Cartography } \\
\text { Land use }\end{array}$ \\
\hline \multicolumn{3}{|l|}{ European Scope } \\
\hline $\begin{array}{l}\text { INSPIRE } \\
\text { Infrastructure for } \\
\text { Spatial Information in } \\
\text { Europe }\end{array}$ & $\underline{\text { https://inspire.ec.europa.eu/ }}$ & $\begin{array}{l}\text { Inspire in each country } \\
\text { (Spatial information) }\end{array}$ \\
\hline $\begin{array}{l}\text { CORINE Land Cover } \\
\text { (Information on the } \\
\text { Environment) }\end{array}$ & $\begin{array}{l}\underline{\text { http://www.eea.europa.eu/publications/COR0- }} \\
\underline{\text { landcover }}\end{array}$ & $\begin{array}{l}\text { Land cover } \\
\text { Europe }\end{array}$ \\
\hline \multicolumn{3}{|l|}{ Worldwide Scope } \\
\hline Bing Maps & ittps://www.bing.com/maps/ & Bird's eye view \\
\hline
\end{tabular}




\begin{tabular}{lll} 
Google Maps & & Streetside view \\
https://www.google.es/maps & 3D Buildings view \\
Google Earth & https://www.google.es/intl/es/earth/index.html & Virtual globe view \\
Google Timelapse & $\underline{\text { https://earthengine.google.com/timelapse/ }}$ & $\begin{array}{l}\text { Dynamic urban } \\
\text { expansion }\end{array}$ \\
Google Earth Engine & $\underline{\text { https://earthengine.google.com/ }}$ & $\begin{array}{l}\text { Analysis of geospatial } \\
\text { information }\end{array}$ \\
Open Street Map & $\underline{\text { https://www.openstreetmap.org/ }}$ & Cartography \\
\hline
\end{tabular}

\subsection{Evaluation of teaching experience}

The majority of students value the GIS-based learning methodology very positively and complete their learning successfully. We have student dropout rates below 5\%. The following graphs (Fig. 8) show the average degree of success achieved by the students in line with the achievement of the course's objectives. The learning curves are shown for the fifteen weeks of duration of the courses.

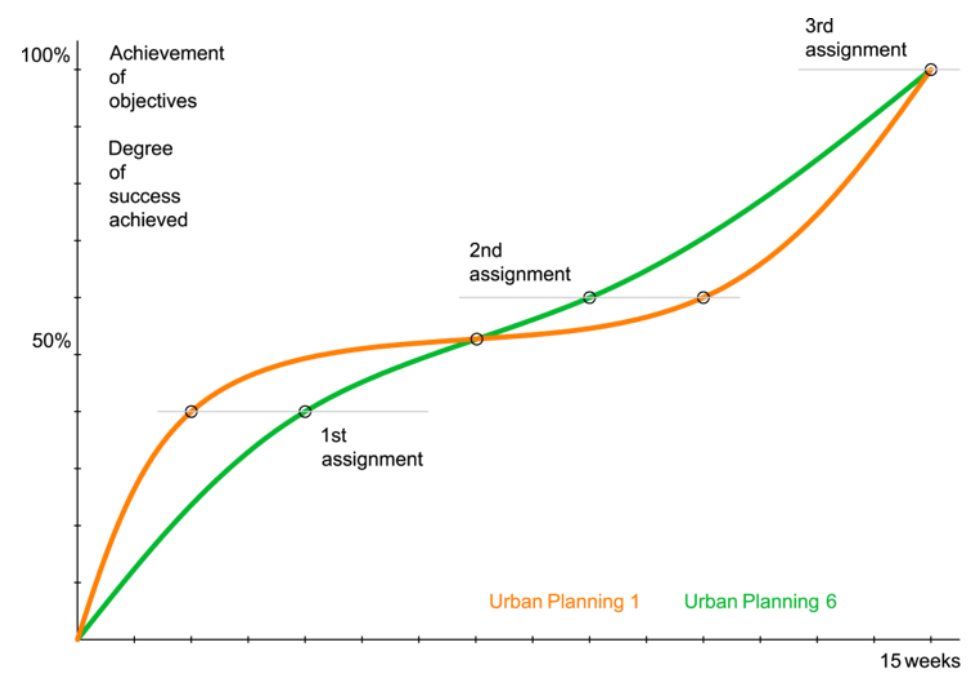

Fig 8. Learning curves. Success achieved by the students in line with the achievement of course objectives.

In both subjects, a continuous assessment of learning is conducted. Students have to perform three main assignments during the course. In the case of Urban Planning 1, students learn quickly during the first few weeks in which they acquire new knowledge and the ability to use GIS. After this first stage, the pace of learning slows as students consolidate their acquired 
knowledge, skills and abilities. During the final weeks of the course, students are able to make their own discoveries, using GIS tools, and learning is deeper. In short, they have begun to learn how to learn, how to make inquiries for themselves and to contribute new points of view. In the case of Urban Planning 6, students already have knowledge, skills and abilities acquired in previous courses of urban planning and learning is produced more progressively throughout the course. In this way, learning starts to produce something slower in the first weeks but ends up producing something faster in the last weeks. The turning point occurs almost halfway through the course, when the subject objectives have been achieved by $50 \%$. In this more advanced subject, students perform their own analyses and discoveries, using the GIS tool, from start to finish of the course.

As mentioned above, the impact of GIS on learning activity has been very important and positive. The most relevant data that corroborates this is undoubtedly the decrease in the dropout rate, which has been reduced by up to $50 \%$. This decrease in student dropout is due to and proportional to the greater motivation they feel when carrying out learning activities. It is also worth noting the high rates of efficiency and success being obtained in the subjects, clearly due to the greater interest that students take in developing the proposed learning activities. These ratios are over $90 \%$ throughout the courses in which the experience is being carried out, with an increase over previous experiences of up to $10 \%$.

GIS are significantly changing the approach to teaching urban planning. However, their use is not yet widespread as a basis for teaching methodology in the degree of Architecture. In spite of their acceptance by students, the use of Computer Aided Design (CAD) programs continues to be in the majority. The students find in these programs better features to design the final composition of the maps they perform. 
As a result of the analysis of the work done with students and our own teaching experience in the subject, we have experienced the following challenges:

(i) Technological: the lack of technical means is an important challenge of using GIS for education. Although students usually have their own laptop, classrooms are not always adapted for computer use and Internet connection is not the most suitable. On other matters, given the limited time of the sessions of the course, unexpected errors the development of assignments may imply substantial changes in the planning of teaching. In addition, technological changes also require constant updating. This issue requires an effort by educational institutions to provide proper technological infrastructures.

(ii) Usability: several usability problems have been identified that slows their learning progress. These problems are related to search operations and with the comprehension of the user interface, map visualization and map tools. Regarding the user interface, there are some defects that can cause misconceptions and a lack of understanding by students. For example, some cases involve the use of colours and unintuitive symbols to represent the graphs. The continuous improvement of the usability of these GIS platforms as well as the interoperability between them, are important challenges for the future. Nevertheless, as the academic year progresses, students usually overcome this issue.

(iii) Data coherence and quality of data: some inconsistencies have been detected working with different GIS of table 3. Geographic information provided does not match. The differences are not only in the appearance of the images generated-colour palette and resolution — but also on the data accompanying the results. Clusters of information and aggregate data are also different. This issue requires to explain students the reasons for those incoherencies 
and decide the right results in any case. For example, Fig. 9 shows the results generated with the same search criteria using different GIS tools.

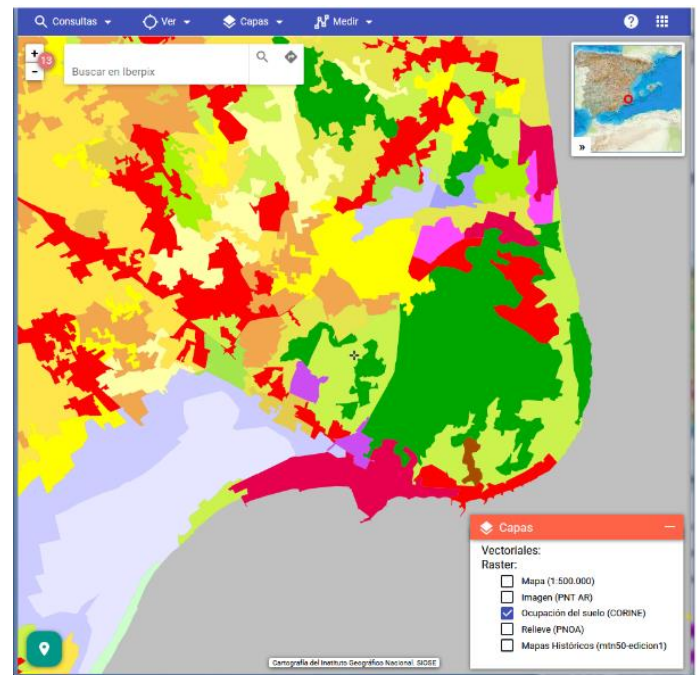

a)

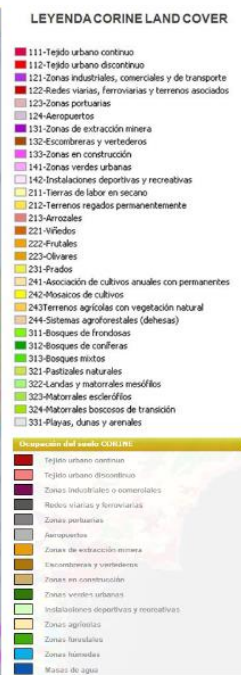

:

Fig. 9. Results generated by use of land request. Application used: a) Nacional Geographic InstituteIberpix; b) Urban Information System.

As can be seen, the images obtained are different. Additional work should be made by GIS providers in order to achieve common representation of data.

(iv) Promoting thinking and reasoning with maps: in our opinion this is the most important challenge because it goes beyond learning how to use the tools and interpret the results. It consists of understanding the capabilities of a GIS and developing spatial reasoning skills which are central to creating better-equipped workers for whatever vocation. Future professionals must understand this new environment and be able to develop innovative applications to meet the needs and complexity of the 21 st century. From our experience, classroom activities should be complex enough to promote think with maps and reasoning about it to solve problems. For example, problems that may involve real-world data, identifying spatial distributions, and creating visual patters. It will be achieved in the second subject and has more to do with the maturity of students with the tool and the potential of the technology. 
The findings of this study are consistent with previous ones (Rickles and Ellul, 2015; Mathews and Wikle, 2019; Han, 2019). However, these issues must be object of further research in order to support especially the teaching-learning processes. For example, by developing ontologies, layers of knowledge management, and semantic web interfaces for students and future professionals.

The increasing use of data and technology in education enables to implement strategies for analysing student academic success (Knight et al., 2020). In this line, there are a growing number of studies on the use of Learning Analytics for "understanding and optimizing learning and the environments in which it occurs" (Ferguson, 2012). These techniques allow teachers to design activities, contents and subjects in order to maximize the students' learning potential (Michos and Hernández-Leo, 2020) and help teachers to adapt their practices to meet students' needs (Rienties and Jones, 2019). In recent times, there is an increasing interest of educators for introducing Learning Analytics into their teaching (Shibani et al., 2020).

In the subjects analysed in this work, the knowledge about teaching strategies usually relied on the expertise of the teachers and previous experiences with students. However, the obtained results of this work provide valuable insights into the performance of students that can be a significant help in the planning of future teaching activities with GIS. In a certain sense, teachers put in practice a learning analytics technique to collect, measurement and analysis data about learning with GIS tools in order to understanding and optimising the learning process. The idea behind it is the students can maximise their learning experience and knowledge of urban planning subjects and engage them in their own learning by using GIS. 


\subsection{Research questions}

The research questions asked above can now be addressed.

(A) Why should efforts be focused on GIS education and what is the impact of applying GIS in teaching-learning processes?

GIS technology plays an important role in the activities of everyday life and the world of work. World operates increasingly driven by the flow of information, and interfaces and underlying codes that allow access to this information have become powerful social forces. It is therefore necessary to educate an informed citizenry able to understand the strengths and weaknesses of technologies and GIS. This technology enables working with geographical or spatial georeferenced data together with different land resources databases in an integrated way. This is a major step forward for creating knowledge by means computerized methods (e.g. automatic image processing, big data analytics, etc.) and entails a great potential for research and teaching. In addition, in professional performance, decision-making almost always involves geographical reasons or relationships (Healy and Walshe, 2020).

Therefore, GIS have an added social value that responds to the reality and needs of the 21 st century. They condition the importance that issues such as location, distance, access to goods and services or public participation have on society. GIS helps to understand and manage large amounts of data. Big data is transforming today's society and is being incorporated around smart cities in which all elements are interconnected. For this reason, the study of curricular contents related with STEM degrees education cannot be understood today without the support of GIS. The geographical perspective that GIS have incorporated into the learning process has improved the understanding of the world and the societies that inhabit it. The acquisition of these space skills and the ability to process and apply large amounts of data will enable future 
professionals to bring prosperity to our society and develop new approaches that are more appropriate and in line with real needs (Longley et al, 2015).

In addition, the use of GIS in teaching is a first approach of the students to the scientific community and its way of working, being essential communicating and exchanging geographic information to expand the knowledge of the different groups beyond its own boundaries, physical or technological (Spielman, 2014).

On the other hand, an elementary statistical analysis of student performance obtained as a synthesis of the educational experience that supports this research, enables us to confirm the positive impact of applying GIS in the teaching-learning processes (Fig. 10). Two fundamental aspects have been analyzed and evaluated: the attitude of students towards the learning experience and the results obtained, both factors being directly related.

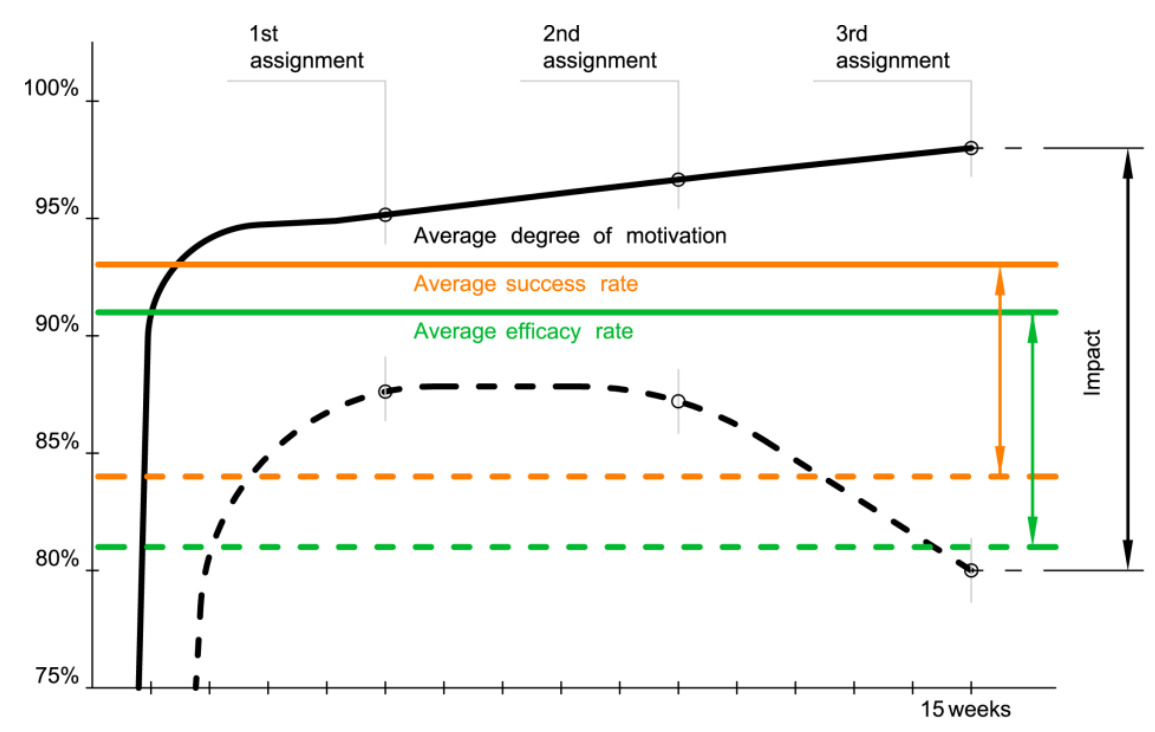

Fig. 10. Impact assessment of applying GIS in the teaching-learning processes.

At the beginning of the experience, it is very significant the speed with which it is possible to get the students' attention, slightly higher in the subjects of the first years of the degree, very possibly due to the novelty of experiencing a new tool close to the profession that 
they have never used before, which entails a good rhythm of work on the part of the students and the obtaining of results from the first weeks of the course. The motivation of the students remains practically constant throughout the whole experience with a tendency to a slight growth, punctually appreciating a greater degree of motivation with the beginning of each new task. This constant rhythm is also noticed in the learning results that are obtained progressively throughout the course. The average degree of motivation valued by the students and observed by the teachers is between $90 \%$ and $95 \%$. These average values of the degree of initial motivation and throughout the development of the teaching activity are also reflected in the academic indices of effectiveness and success, the average values being, as already mentioned, above $90 \%$.

The discussion of these data enables us to affirm that the use of GIS, regardless of whether they are courses in the first or last years of the degree, does not have to imply a greater difficulty for the students at the time of passing the subjects, quite the contrary. This new way of bringing teaching closer to real spatial problems through GIS and the confidence that this tool gives students to reason and justify their proposals based on data are precisely the factors that lead to a high degree of general motivation. This high degree of general motivation has undoubtedly been, in our case, the factor that has determined the achievement of very good results. If we also take into account the high degree of autonomy that the use of GIS provides to students, we can affirm that teaching methodologies based on GIS are widely accepted by students, which has a great positive impact on efficiency and success rates, as well as dropout rates, as shown in this research. Even when punctually the evaluations of the assignments made during the course have not been high grades, the satisfaction of the students has been high, recognizing that they have learned. Students are fully aware that learning using GIS brings them a little closer to the reality of spatial problems and the professional environment. 
(B) Is GIS as a methodology more effective than other methods for education?

The quality that makes GIS and their applications online in valuable technological teaching tools is the fact of combining spatially referenced databases, new technologies (ICT), media and analytical tools. Own GIS software architecture facilitates the design of methodologies for teaching, in an orderly way: prioritize issues, understand them, consider alternatives and reach viable conclusions. The potential of GIS to access information and manage large amounts of data, as well as to produce knowledge, overcomes the limitations of other affordable methods. In a first phase, GIS help students manage information and facilitate its organization, access, retrieval and manipulation. The data can be treated in different formats: alphanumeric, vector, raster. The data are processed and stored, enabling different testing procedures, as well as a simple visualization and export of data (Longley et al, 2015). In a second phase of problem-solving, GIS help students to contextualise different conflicts and increase their ability to both evaluate possible alternatives as consider different opinions, thus supporting decision-making. Therefore, a complete learning process based on methodologies similar to those used in professional practice is built. In general, the majority of students valued very positively the usefulness of their learning process in geospatial technologies, understanding that the activities involve a geographical component that matters in decision-making.

Thus, in comparison with other methodologies in the discipline, which have traditionally consisted of providing equal statements for all students and periodically correcting the solutions proposed by them until an adequate level of learning is achieved, GIS-based methodologies present four main differences that are evident in this research: Firstly, the free access of students to a great variety of information to address the projects, beyond the information that was traditionally provided only by the teacher; secondly, a wide range of possibilities for analysis, 
enhancing the creativity of students and enabling better reasoning and justification of the solutions adopted; thirdly, an approach to reality and real spatial problems; and fourthly, a high degree of autonomy, in line with current European education policy and the development of professional practice.

In addition, Architecture and Engineering students have good technological skills, for this reason, the use of GIS facilitates the teaching-learning processes, since it introduces an additional motivational aspect that is essential to awaken the interest of all students, without differences in previous levels of qualification or gender. No major difficulties were noted in this study in the learning of the students who enrol for the first time; almost all students whose learning experience has been analysed were taking the subjects for the first time, with a few exceptions. This is due to the good technological skills that the students already have when they start a technical degree like Architecture, and to the motivational power that the use of GIS technology supposes. Gender differences were not noticed either, since, in the field of Architecture studies both female and male students have equally good technological skills and great motivation and interest in learning technological tools.

\section{CONCLUSIONS AND FUTURE WORK}

The use of GIS in educational process is very common in STEM studies. Introducing new technologies into the classroom is increasingly to train students adequately in today's information and communications society, in which big data is having a great transformative impact. That is why the technologies that enable data processing and analysis, such as GIS in the case of spatial data, are the most demanded in the professional sector.

Some qualitative results from the analysis of the teaching-learning experiences following a GIS-based methodology can be drawn which summarize the answer to the research questions: 
in first place, it enables a better learning of urban planning concepts, city shape and territory features; secondly, the students can understand how knowledge is constructed in active land data research. It allows them to infer new valuable knowledge by designing their own data analysis to find out the required information in each case. It is very helpful for performing the students' future profession and useful for decision making; other important outcome is that these tools enhance the students' motivation; and finally, it facilitates engaging them in social issues such as environmental protection and the sustainability agenda.

GIS application can also benefit other subjects that do not use the tool in their learning process because the skills it provides help students to think and to work with spatial data. For this reason, it is important including GIS skills in the curriculum of STEM university degrees. In the case of GIS, for example, it is very useful in smart city designs in order to geo-positioning smart sensors and service points along the city such as street video cameras and RFID sensors (PérezdelHoyo et al., 2017; Mora et al., 2019).

However, some improvements should be carrying out to increase the effectiveness of teaching-learning processes, especially in the scope of integration with other technologies, interoperability, and developing of reasoning process tools about data.

From our experience as teachers and professional, the proposals should be directed toward facilitating learning and understanding geographical information by students. Basically, these proposals consist in evolving GIS to advanced web schemes, building collaborative work environments, developing a body of knowledge that gives coherence and homogenize the subject matter being studied, and in building a semantic web interface to provide this knowledge specifically to students and professionals. 
Future development work should be along the lines of developing the proposed ideas, especially the knowledge management as ontologies and building smarter web interfaces. These initiatives will promote teaching in complex disciplines in the field of engineering education and will allow to make the most of these tools. In addition, the evaluation of the proposed solutions is an important matter that requires a time for experimentation with the students and a careful empirical effort that we plan to consider in the future potential work.

Additional inquiry processes are recommendable in order to further develop the analysis of data and obtain valuable connection between learning analytics and the design of teaching in using technological tools such as GIS.

\section{Acknowledgment}

This study was supported by the Spanish Research Agency and the European Regional Development Fund under project CloudDriver4Industry TIN2017-89266-R.

\section{References}

E. Abad-Segura, M.D. González-Zamar, J.C. Infante-Moro, G. Ruipérez García. Sustainable Management of Digital Transformation in Higher Education: Global Research Trends. Sustainability, 12, (2020) 2107. https://doi.org/10.3390/su12052107

A. Afrooz, L. Ding, C. Pettit, An Immersive 3D Virtual Environment to Support Collaborative Learning and Teaching, Computational Urban Planning and Management for Smart Cities, Lecture Notes in Geoinformation and Cartography. (2019). https://doi.org/10.1007/978-3-030-19424-6_15

T. Argles. Teaching practical science online using GIS: a cautionary tale of coping strategies, Journal of Geography in Higher Education, 41 (2017) 3:341-352, https://doi.org/10.1080/03098265.2017.1315531

T.R. Baker, WebGIS in Education. Geospatial Technologies and Geography Education in a Changing World, Advances in Geographical and Environmental Sciences, (2015) 105115. https://doi.org/10.1007/978-4-431-55519-3_9

M. Basaraner et al. Cartography and GIS Education in Geomatic Engineering, International Conference on Cartography \& GIS, At Riviera, (2014). Bulgaria

K.S. Bitting, M.J. McCartney, K.R. Denning, and J.A. Roberts, J.A. (2018), Conceptual Learning Outcomes of Virtual Experiential Learning: Results of Google Earth Exploration in Introductory Geoscience Courses, Research in Science Education, 48(3): 533-548. https://doi.org/10.1007/s11165-016-9577-z 
N. Bearman et al., The future role of GIS education in creating critical spatial thinkers, Journal of Geography in Higher Education, 40 (2016) (3): 394-408. https://doi.org/10.1080/03098265.2016.1144729

T. Carlson, A Field-Based Learning Experience for Introductory Level GIS Students, Journal of Geography 106 (2007) (5):193-198. https://doi.org/10.1080/00221340701697636

S. Chen, D. Zhuang, Evolution and Evaluation of the Guangzhou Metro Network Topology Based on an Integration of Complex Network Analysis and GIS. Sustainability 12. (2020), 538. https://doi.org/10.3390/su12020538

M. Corrales-Serrano, J. Sánchez-Martín, J. Moreno-Losada, F. Zamora-Polo. GIS in the History Classroom: Displaying the Walls of Elvas and Badajoz through the Use of Google Earth. Proceedings38 (2019), 2. https://doi.org/10.3390/proceedings2019038002

A. Dardas. Why GIS and Computer Science Should Integrate Together?, Education \& Research Canada. (2018) Available online at: https://ecce.esri.ca/wpecce/2016/12/02/why-gis-andcomputer-science-should-integrate-together/, (Accessed on 17-01-2020).

R. DeMiguel-González, M.L. DeLázaro-Torres, WebGIS Implementation and Effectiveness in Secondary Education Using the Digital Atlas for Schools, Journal of Geography, 119 (2020) 2. https://doi.org/10.1080/00221341.2020.1726991

E. E. Egiebor, E. J. Foster. Students' Perceptions of Their Engagement Using GIS-Story Maps, Journal of Geography, 118 (2019) (2). https://doi.org/10.1080/00221341.2018.1515975

S. Elwood. Integrating Participatory Action Research and GIS Education: Negotiating Methodologies, Politics and Technologies, Journal of Geography in Higher Education, 33 (2009) (1):51-65. https://doi.org/10.1080/03098260802276565

R. Ferguson, Learning analytics: Drivers, developments and challenges, International Journal of

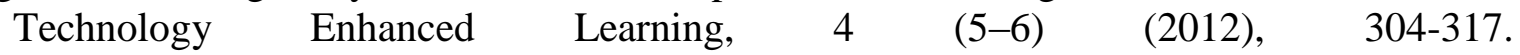
https://doi.org/10.1504/IJTEL.2012.051816

C. Goldsmith. How, and to what extent do Geographical Information Systems (GIS) contribute to student engagement with Service Learning project?, Master Thesis. University of Oxford. Available online at: https://ora.ox.ac.uk/objects/uuid:2115f5ad-3fc2-43e4-8cba17a515aef859, accessed on 13/04/2020.

R. Han. Web GIS in Development: From Research and Teaching Perspectives. GIScience Teaching and Learning Perspectives. Advances in Geographic Information Science. (2019). Springer, Cham. https://doi.org/10.1007/978-3-030-06058-9_7

G. Healy, N. Walshe, Real-world geographers and geography students using GIS: relevance, everyday applications and the development of geographical knowledge, International Research in Geographical and Environmental Education, 29 (2020) (2). https://doi.org/10.1080/10382046.2019.1661125

E.A. Jant et al., Defining and Measuring the Influences of GIS-Based Instruction on Students' STEM-Relevant Reasoning, Journal of Geography, 119 (2020) 22-31. https://doi.org/10.1080/00221341.2019.1676819

I. Jo, J. Eun-Hong \& K. Verma, Facilitating spatial thinking in world geography using Webbased GIS, Journal of Geography in Higher Education, 40 (2016), 3:442-459. https://doi.org/10.1080/03098265.2016.1150439

S. Knight, A. Gibson, A. Shibani, Implementing learning analytics for learning impact: Taking tools to task, The Internet and Higher Education, 45 (2020) 100729. https://doi.org/10.1016/j.iheduc.2020.100729 
M. Kim, R. Bednarz, Development of critical spatial thinking through GIS learning, Journal of Geography in Higher Education, $37 \quad$ (2013) https://doi.org/10.1080/03098265.2013.769091

M.G. Korucu. GIS and Types of GIS Education Programs, Procedia - Social and Behavioral Sciences, 46 (2012). 209-215. doi: https://doi.org/10.1016/j.sbspro.2012.05.095

D. Livingstone, K. Lynch, Group Project Work and Student-centred Active Learning: Two different experiences, Studies in Higher Education, 25, (2010) (3): 325-345. https://doi.org/10.1080/713696161

P.A. Longley, M.F., Goodchild, D.J. Maguire, D.W. Rhind, Geographic Information Science and Systems, John Wiley \& Sons. 4th Ed. (2015) ISBN: 978-1-118-67695-0

A. J. Mathews, T. A. Wikle. GIS\&T pedagogies and instructional challenges in higher education: A survey of educators, Transactions in GIS. 23 (2019) 5: 892-907. https://doi.org/10.1111/tgis.12534

K. Michos, D. Hernández-Leo, CIDA: A collective inquiry framework to study and support teachers as designers in technological environments, Computers \& Education, 143 (2020) 103679. https://doi.org/10.1016/j.compedu.2019.103679

H Mora, J Peral, A Ferrández, D Gil, J Szymanski, Distributed Architectures for Intensive Urban Computing: A Case Study on Smart Lighting for Sustainable Cities, IEEE Access 7 (2019), 58449-58465. https://doi.org/10.1109/ACCESS.2019.2914613

H. Mora H., MT. Signes-Pont, A. Fuster-Guilló, ML. Pertegal-Felices, A collaborative working model for enhancing the learning process of science \& engineering students, Computers in Human Behavior, 103 (2020) 140-150. https://doi.org/10.1016/j.chb.2019.09.008

R. Molina-Carmona, M. L. Pertegal-Felices, A. Jimeno-Morenilla, H. Mora-Mora, Assessing the impact of Virtual Reality on engineering students' spatial ability, The Future of Innovation and Technology in Education: Policies and Practices for Teaching and Learning Excellence (Emerald Studies in Higher Education, Innovation and Technology), Emerald Publishing Limited, (2018) pp. 171-185. https://doi.org/10.1108/978-1-78756$\underline{555-520181013}$

A. Moore et al., Comparative usability of an augmented reality sandtable and 3D GIS for education, International Journal of Geographical Information Science, 34 (2020) (2). https://doi.org/10.1080/13658816.2019.1656810

E. Norton, Y. Li, L.R. Mason, R.A. Washington-Allen, Assessing the Impact of a Geospatial Data Collection App on Student Engagement in Environmental Education. Education Sciences. 9, (2019), 118. https://doi.org/10.3390/educsci9020118

K. Ooms, P. De Maeyer, B. De Wit, R. Maddens, T. Nuttens, N. Van de Weghe, S. Vervust. Design and use of web lectures to enhance GIS teaching and learning strategies: the students' opinions. Cartography and Geographic Information Science. 42 (2015) 3:27182. doi: https://doi.org/10.1080/15230406.2015.1011236

S. Peirce. Making Learning Mobile: Using Mobile Technologies to Bring GIS into the Geography Classroom. Teaching Innovation Projects, 6 (2016) (1). Available online at: https://ojs.lib.uwo.ca/index.php/tips/article/view/3705, accessed on 13/04/2020.

R. Pérez-delHoyo, C. Garcia-Mayor, H. Mora, V. Gilart, M.D. Andújar-Montoya, Improving Urban Accessibility: A Methodology for Urban Dynamics Analysis in Smart, Sustainable and Inclusive Cities, International Journal of Sustainable Development and Planning. 12 (2017) (3):357-367. https://doi.org/10.2495/SDP-V12-N3-357-367 
W.A. Powell, Using Geospatial Technology to Promote Middle School Students' Critical Thinking on Socioscientific Issues, Next Generation Digital Tools and Applications for Teaching and Learning Enhancement. Ed. IGI-Global, ISBN13: 9781799817703. (2020). 47-78. https://doi.org/10.4018/978-1-7998-1770-3.ch004

B. Ricker, J. Thatcher. Evolving technology, shifting expectations: cultivating pedagogy for a rapidly changing GIS landscape, Journal of Geography in Higher Education, 41 (2017) 3. https://doi.org/10.1080/03098265.2017.1315533

P. Rickles, C. Ellul, A Preliminary Investigation into the Challenges of Learning GIS in Interdisciplinary Research, Journal of Geography in Higher Education, 39 (2015) (2). https://doi.org/10.1080/03098265.2014.956297

B. Rienties, A. Jones. Evidence -Based Learning: Futures. Using learning design and learning analytics to empower teachers to meet students' diverse needs. In: Ferguson, Rebecca; Jones, Ann and Scanlon, Eileen eds. Educational Visions: The lessons from 40 years of innovation. London: Ubiquity Press, (2019) pp. 109-125. https://doi.org/10.5334/bcg.g

A. Shibani, S. Knight, S.B. Shum, Educator perspectives on learning analytics in classroom practice, The Internet and Higher Education, $46 \quad$ (2020) 100730. https://doi.org/10.1016/j.iheduc.2020.100730

S.E. Spielman, Spatial Collective Intelligence? Credibility, Accuracy, and Volunteered Geographic Information, Cartography and Geographic Information Science, 41 (2014) 2: 115-124. https://doi.org/10.1080/15230406.2013.874200

J. Stoltman, J. Lidstone, and G. Kidman. The 2016 International Charter on Geographical Education. International Research in Geographical and Environmental Education 26 (2017) (1):1-2. doi: https://doi.org/10.1080/10382046.2017.1272849

C. Wang, C.M. Kantor, J.T. Mitchell, T.S. Bacastow T.S. Digital Earth Education, Manual of Digital Earth. Springer, Singapore. (2020) https://doi.org/10.1007/978-981-32-9915-3_24

G. Yu, M. Xie, J. Liang, A. Farooq \& E. J. Williams, A GIS-based 3D slope stability analysis method based on the assumed normal stress on the slip surface, Scientific Reports volume 10, Article number: 4442 (2020). https://doi.org/10.1038/s41598-020-61301-X

X. Xiang, Y. Liu. Exploring and enhancing spatial thinking skills: Learning differences of university students within a web- based GIS mapping environment, 50 (2019) (4): 18651881. https://doi.org/10.1111/bjet.12677

H. Xie, Y. He, C. Choi, C. Chen, H. Cheng. Warning of negative effects of land-use changes on ecological security based on GIS, Science of The Total Environment, 704, (2020), 135427. https://doi.org/10.1016/j.scitotenv.2019.135427 